Check for updates

The DataLab, Nuffield Department of Primary Care Health Sciences, University of Oxford, Oxford, UK

Correspondence to: B Goldacre ben.goldacre@phc.ox.ac.uk Cite this as: $B M / 2020 ; 370: \mathrm{m} 2607$ http://dx.doi.org/10.1136/bmj.m2607 Published: 17 July 2020

\section{The NHS deserves better use of hospital medicines data}

Ben Goldacre and Brian MacKenna argue that hospital medicines data has huge potential to improve patient care and that its use for public good is being blocked by cultural, contractual, and political barriers, rather than technical complexity

\section{Ben Goldacre, Brian MacKenna}

In 2016-17 the NHS in England spent £17.4bn (€19.1bn; \$21.4bn) on medicines, ${ }^{1}$ approximately $14 \%$ of the entire NHS budget. Expenditure on medicines has risen rapidly from Ł13bn in 2010-11, mainly due to expansion in hospital prescribing from $£ 4.2 \mathrm{bn}$ to $£ 8.3$ bn over six years (fig 1 ). Any business faced with costs doubling would invest in data-"business analytics"-to identify opportunities for better practice. Primary care prescribing data has been widely shared and analysed, within and outside the NHS. Conversely, although secondary care is where most new medicines are used, ${ }^{2}$ there is little publicly accessible data on what is prescribed and dispensed in each hospital. This effectively blocks work to identify variation and signals indicative of suboptimal care.

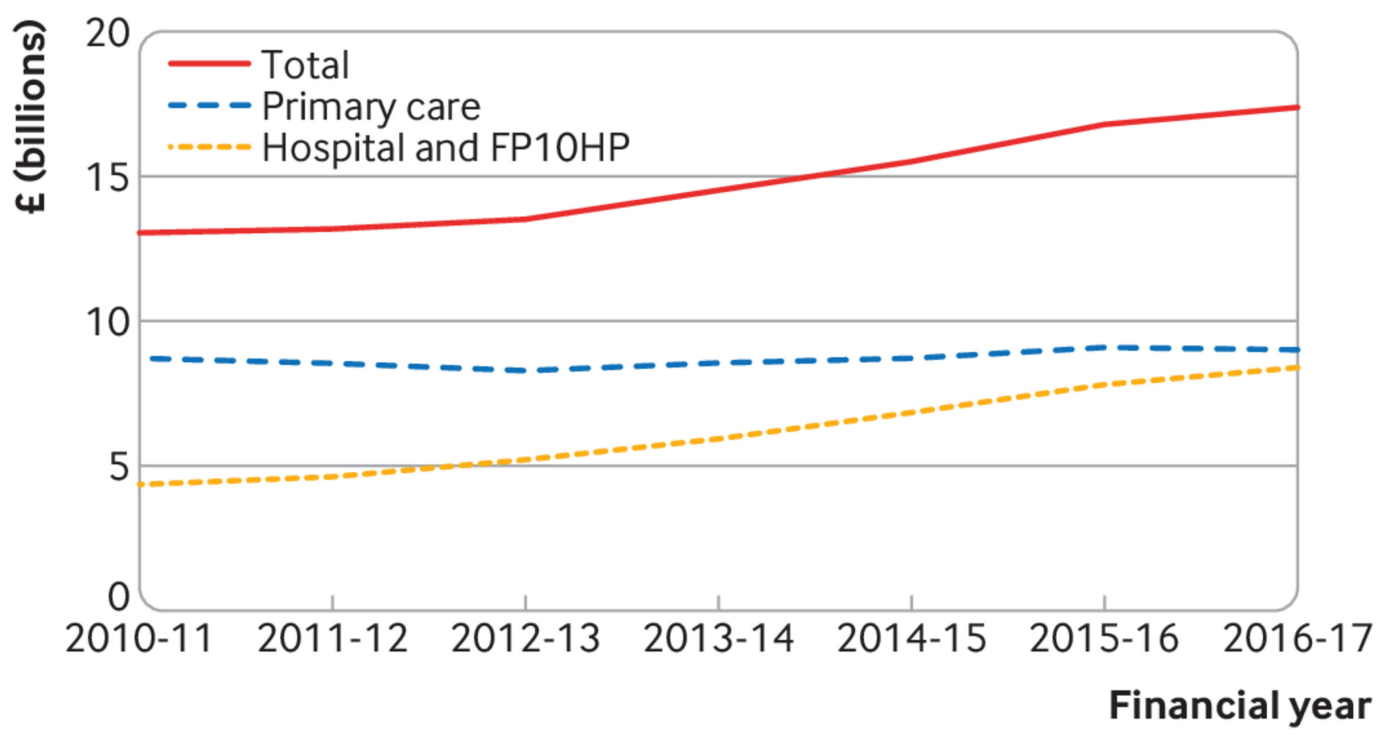

Fig 1 | Prescribing costs in primary and secondary care. Source: NHS Digital ${ }^{1}$

Access to hospital medicines data is commonly discussed as a technical issue. ${ }^{34}$ In reality, there are no technical barriers: data is currently extracted, aggregated, and normalised into one national dataset through at least two systems. Access to this data, however, is limited by a complex network of commercial contracts, apparent resistance to transparency at some NHS trusts, and historical reluctance to make change at a policy level. We argue that all currently aggregated NHS hospital medicines supply data should be shared immediately for third party analysis, to help reduce costs and improve patient care.

\section{Primary care prescribing data and the benefits of open audit}

GP prescribing data has been gathered nationally and shared with a small number of named local NHS staff for review since at least 1988. Since September 2011, monthly data on NHS GP prescribing has been publicly shared at a high level of granularity, down to individual general practice level, as open data for all to analyse with no information governance barriers. ${ }^{5}$ Data sharing has supported a rich ecosystem of analyses, tools, and approaches including clinical commissioning group medicines optimisation teams who monitor data and give feedback to GPs and online services that give open access to prescribing patterns and trends. Analyses conducted in this dataset have also underpinned original research on a diverse range of topics, ${ }^{6-15}$ and data feedback to GPs has been shown to improve prescribing. ${ }^{16-19}$ Our group produces OpenPrescribing.net where any user can explore all prescriptions at any individual practice, explore outliers, and see changes in prescribing patterns down to the level of individual months, brands, formulations, and doses, with 135000 unique users over the past year, as well as published peer reviewed evidence of cost savings among users. ${ }^{11}$

\section{Secondary care data: access is restricted}

By contrast, there is almost no publicly accessible data on hospital medicines, only small subsets of 
unhelpfully aggregated data on single topics (such as antibiotics and biosimilars). ${ }^{20}{ }^{21}$ Even within the NHS it is hard to access information. ${ }^{22}$ There are longstanding ambitions to improve the collection and dissemination of hospital medicines data through broader initiatives such as e-prescribing, but these programmes are long overdue and, as with all such initiatives, may never deliver on current plans.

Moreover, access to hospital medicines data is not a technical challenge awaiting a novel technical solution because this data already exists, nationally aggregated, at high resolution, and in a form that would enable extensive high quality analysis to be delivered immediately. Each hospital holds detailed data describing what was supplied from the pharmacy each month including drug names, brands, formulation, strength, and prices (boxes 1,2,3). Access to this data is restricted, not by technical issues, but by political, cultural, and contractual barriers. In boxes 1, 2, and 3 we describe our understanding of three national systems that already aggregate this medicines data, some paid for by the public purse, and describe how data has been kept inaccessible. We know of various further sources of hospital medicines data; all is similarly inaccessible for the purposes we describe or contains only small aggregated cuts of data. ${ }^{36-39}$

\section{Box 1: IQVIA}

IQVIA (previously QuintilesIMS and IMS Health) is a large multinational company ${ }^{23}$ that collects and sells medicines usage data, principally to support pharmaceutical marketing activity. ${ }^{23}$ For two decades it has purchased and aggregated medicines supply data from NHS hospital pharmacy systems, then sold it to industry. ${ }^{24}$ Typically, NHS hospitals are paid a small amount to supply this data and also receive some dashboards developed by IQVIA to compare their prescribing with the national average.

A small proportion of this data is also made available to NHS Digital for publication as the Hospital Pharmacy Audit Index database. However, access is restricted under the terms of an agreement entered into by NHS Digital and IQVIA. ${ }^{1}$ The NHS cannot publish or pass on this information or any analyses derived from it to any other party, except where the data is published in response to a parliamentary question, questions about products approved by the National Institute for Health and Care Excellence, or as part of an NHS Digital publication. No data can be released that might identify any NHS trust or hospital in any way. No data can be released until six months after it was collected. No data can be released even to a UK regulatory or advisory body, outside a narrow range of specific circumstances, without prior permission from IQVIA. No data can be released using molecule brand names, or on any individual chemical that is still under patent.

This hospital medicines supply data already exists. It is provided by NHS hospitals to the drug industry for marketing purposes. But the restrictive terms of the NHS's agreement with IQVIA mean that we are unable to use it for open audit to improve quality, reduce avoidable expense, and make prescribing safer in hospitals. Furthermore, NHS Digital, the NHS body with the remit to "harness the power of information and technology to improve health and care," 25 is unable to use this detailed hospital medicines data to conduct audits for feedback to clinicians.

\section{Box 2: Rx-Info and DEFINE}

Rx-Info is a company based in the UK that collects medicines supply data from NHS trusts, "normalises" it so that data from different trusts is in a comparable format, and then makes it available in a single place, through a tool called DEFINE. An NHS trust can generate comparative reports for each hospital, benchmarking their medicines data against their peers through a range of reports focusing on choice of medicine, cost, clinical specialty usage, and derived indicators for safe choice of medicines. This system covers over $90 \%$ of hospitals. But the data can be viewed only by the hospitals that choose to participate. ${ }^{26}$ Hospitals are only allowed to see their own data, however, and benchmarking against peers that Rx-Info considers similar. ${ }^{27}$ The methods used to create benchmarks and measures are not disclosed. We are unable to give further information about the contents or outputs of DEFINE because there is no information on the agreements between any NHS organisation and Rx-Info in the public domain; no documentation to describe the data they collect; and no documentation or description of what is done with the data.

It is sometimes claimed that data aggregation projects such as these are expensive. Although the information is not readily available, a handful of freedom of information requests are available in the public

domain. ${ }^{28-31}$ These indicate that hospitals pay approximately $f_{5000}$ to f10 000 per year to Rx-Info, meaning the total project cost is approximately $f 1 \mathrm{~m}$ to $\mathrm{f} 2 \mathrm{~m}$ a year. This is not just to aggregate the data, but also to produce whatever analyses or dashboards are created. The work is not trivial, and some "data normalisation" is required to account for different data standards, time periods, and so on. This is achievable and rudimentary work, however, all completed against a modest annual income: there are no insurmountable technical barriers here, by any means.

As with the IQVIA data, this hospital medicines supply data already exists. It is nationally aggregated and in a form that can be used for analysis to improve patient care and efficiency. Furthermore, the data collection and aggregation have already been paid for by the public purse. But because of the commissioning model used, with individual trusts contracting to the data aggregation company used, this data is not available for open audit.

\section{Box 3: NHS Improvement and the Model Hospital}

NHS Improvement is responsible for supporting trusts to "give patients consistently safe, high quality, compassionate care within local health systems that are financially sustainable." 32 The Carter report of 2016 asserted that there were $f_{5} \mathrm{bn}$ worth of potential savings due to unwarranted variation in NHS hospitals 33 and recommended the development of benchmarks. In response, NHS Improvement launched its Model Hospital programme, including a "digital information service" allowing trusts to explore variation and identify any areas for improvement. The Model Hospital data includes a range of measures, including some that relate to medicines, derived from the DEFINE data. But again, access to the Model Hospital data is restricted for NHS trusts and limited sharing within NHS England and NHS Improvement; no other individual, organisation, or research team is permitted access.

Furthermore, no trust can identify any other trust in the data. $33-35$

\section{The risks of limiting access to secondary care data}

Restricted access presents multiple problems. Firstly, it prevents analytic work by teams with the skills and creativity needed to generate actionable insights for diverse groups of users. A recent survey reported data access as a key barrier preventing early career NHS pharmacists using data to inform practice. ${ }^{22}$ Commissioning is spread across hundreds of regional organisations, and all need data to help plan, understand, and improve services. Even clinical commissioning groups are unable to access some NHS hospital medicines data, with occasional exceptions. These are the very organisations responsible for commissioning services from NHS hospitals and that pay for the medicines prescribed in NHS hospitals. ${ }^{40}$

Secondly, closed working models also create barriers to verification, critical review, and collaborative improvement of analytic work. $\mathrm{Rx}$-Info claims that it has saved one trust $£ 110$ ooo a year, but there is no access to the data used, no clear explanation of the methods used, and nothing to identify the trust in which this saving was reportedly made. ${ }^{41}$ NHS Improvement claimed that its Model Hospital service had supported savings of “£324 million in one year” on prescribing costs alone ${ }^{42}$ but initially gave no detail on the 
analytical methods to produce this figure. They later shared an online webinar and one page diagram, after we raised concerns, giving minimal information on the methods used. 43

Because the analytical work by IQVIA, Rx-Info, and NHS Improvement is done behind closed doors, its quality and character are unknown. It cannot be critically reviewed and improved by others with complementary knowledge and expertise in data science or prescribing and is therefore likely to miss opportunities for improving patient care. Conversely, if the work is excellent, nobody can learn from the methods. This falls far short of the vision for open approaches in the NHS set out by the secretary of state for health and social care. ${ }^{44}$ It also falls far short of standard practice in medicine and academia more broadly: although academic researchers show mixed compliance with contemporary standards on sharing data and full analytic code, ${ }^{45}$ it is inconceivable that any substantial claim in medical research could be made without disclosing details of the analytical methods used.

Thirdly, restrictions around data sharing impede innovative approaches to improving quality, safety, and cost effectiveness using medicines data. Independent researchers working on primary care prescribing data have identified whole new categories of cost savings, ${ }^{10}$ novel informatics methods, ${ }^{46}$ and research on the reasons for slow and rapid uptake of evidence in clinical practice. ${ }^{15}$ Hospitals are where new treatments are most likely to be used and where costs are growing fastest; they are therefore where this kind of collaborative analysis is most needed, but it is currently prevented by data access barriers.

Lastly, data access barriers prevent public and independent external scrutiny of hospital activity. Although publicly accessible data can be uncomfortable for organisations and requires thoughtful handling, thoughtful public scrutiny on public services can help build better quality, safer, and more cost effective care.

\section{Arguments against sharing medicines data}

We have struggled to find good arguments against a more open approach to hospital data. It could plausibly be argued that commercial confidentiality around the price negotiated by each hospital for certain medicines may help to reduce acquisition costs; but even with these cost data partially withheld, usage volume data alone could generate potentially transformative insights on quality and safety of prescribing.

It could plausibly be argued that even aggregated medicines data might occasionally identify the treatment choices of patients with rare conditions; but this could readily be addressed with small number suppression or by sharing data confidentially with named third parties. Furthermore, the Information Commissioner has ruled on the same issue in primary care, finding that the odds of re-identification are low and present no barrier to sharing. 47

We recognise concerns about inappropriate analyses being used to create public anxiety. But we also note that the only prominent recent example of prescribing data being used in this way came from the Care Quality Commission, a national government agency, which used prescribing data in its public Intelligent Monitoring programme to inappropriately label one in six general practices as "failing." 48-50 In our view this risk is best mitigated through better education and better management, with occasional missteps balanced against the benefits. We are aware of no further good arguments against sharing medicines data but would welcome an open discussion with those who either oppose or deprioritise such sharing.

\section{How can we get hospital medicines data shared?}

As we have argued, although access to medicines supply data is discussed as a technical issue, in reality the data is already aggregated. The barriers to wider use are cultural, social, and political, rather than technical.

We offer three possible solutions. The NHS could seek to modify the current contracts between NHS hospitals and Rx-Info and negotiate for that existing dataset to be shared with NHS and academic partners. Alternatively, the NHS could seek to acquire this company, which has legitimately invested in gathering and aggregating the information. If both negotiations are unsuccessful, we suggest that the NHS should learn lessons, move on, and pay for the aggregation work to be done twice, as the cost burden is modest. Hospitals could simply be compelled to share data, for national aggregation into an open dataset, through an Information Standards Notice, as with numerous other datasets. ${ }^{51}$ Data aggregated at the level of hospitals could then be shared openly, in the same way that practice level primary care prescribing data is shared.

\section{Better analytics for the NHS}

In our view, the issues around secondary care medicines data exemplify broader shortcomings around better use of data. Responsibility for these problems clearly does not lie with individual commercial vendors such as IQVIA or Rx-Info. The UK has made huge investments to support using NHS data to improve care. But this has largely gone into esoteric "blue skies" and academic research ${ }^{52}$ rather than meeting current service needs. In addition, as we argue above, a culture of conducting analytics for service improvement behind closed doors has held back both innovation and delivery. As a result, we have failed to unlock the potential in huge volumes of existing NHS administrative data.

We think the NHS should abandon its current closed approach, embrace a culture of modern, open methods around analytics, and support diverse teams to compete in generating new insights to improve patient care. This will require a more energetic approach to sharing data and a modest reshaping of the current analytic spend. Specifically the NHS or the Department for Health and Social Care could run open competitive funding calls for teams to produce operational research insights, modelled on conventional competitive academic funding, so that diverse teams of data scientists and clinicians can compete over the best way to use NHS data for service improvement. Funds should be contingent on recipients publishing their methods and sharing their code as open source. This modern, open approach will not only support verification and reach, it will also support practical learning in the workforce.

This approach could pay dividends far beyond medicines data to diverse areas such as bed management, referral pathways, and blood test ordering, to make the NHS a world leader in data driven care. The barriers to this opportunity are not technical, and delivery would be swift.

\section{Conclusion}

Commentators, clinicians, funders and policy makers should be cautious about assuming that technical challenges are the barrier to better use of data. Hospital medicines data is one clear example of how cultural and political barriers continue to block high value analytic work that would rapidly improve patient care. The NHS should promote data sharing and actively embrace an environment where teams of analysts can compete in generating new insights to improve patient care. 


\section{Key messages}

- The NHS has some of the richest health data in the world, but access barriers are blocking its use

- Detailed primary care medicines data is openly shared and has supported a rich ecosystem of approaches to improve quality, safety, and cost effectiveness of patient care

- Detailed hospital data is no more sensitive and is already aggregated in multiple locations, but access is being needlessly restricted

- Hospitals use the newest and most expensive medicines and thus hold the greatest opportunities to manage variation in treatments and costs

- Hospitals have seen the fastest expansion in costs from $f 4.2 \mathrm{bn}$ to f8.3bn over six years

- Policy makers are keen to use data to improve care, but this can only happen when unnecessary access barriers are lifted

Competing interests: All authors have completed the ICMJE uniform disclosure form at www.icmje.org/coi_disclosure.pdf and declare the following: BG is chair of the HealthTech Advisory Board reporting to the Secretary of State for Health and Social Care. He has received research funding from the Laura and John Arnold Foundation, the Wellcome Trust, the Oxford Biomedical Research Centre, the NHS National Institute for Health Research School of Primary Care Research, the Health Foundation, NHS England, and the World Health Organisation; some of this funding is to work on NHS data, including open analysis of NHS prescribing data; he also receives personal income from speaking and writing for lay audiences on the misuse of science. BMK is employed by NHS England working on medicines policy and clinical lead for primary care medicines data. The views expressed are those of the authors and not necessarily those of the NIHR, NHS England, or the Department of Health and Social Care.

Funding: No specific funding was sought for this work. BG's work on clinical informatics is supported by The NIHR Biomedical Research Centre, Oxford; NHS England; the Health Foundation (Award Reference Number 7599); the National Institute for Health Research (NIHR) School of Primary Care Research

(SPCR) (Award Reference Number 327). Funders had no role in the study design, collection, analysis, and interpretation of data; in the writing of the report; and in the decision to submit the article for publication.

Contributors and sources: BG conceived the paper and wrote the first draft. BG and BMK revised and expanded the paper extensively. Both authors contributed to and approved the final manuscript. BG supervised the project, obtained funding, and is guarantor.

We are grateful to the DataLab team for extensive discussions around better use of NHS data, and wider NHS colleagues who have informed our opinions on this topic.

$1 \quad$ NHS Digital. Prescribing costs in hospitals and the community. England 2016-17. https:/digital.nhs.uk/data-and-information/publications/statistical/prescribing-costs-in-hospitals-and-thecommunity/2016-17.

2 Murch L, Rickwood S, McClellan B, Seiter S. Launch Excellence V. Surviving and thriving when launching in an increasingly specialised world. https://www.iqvia.com/-/media/quintilesims/pdfs/launch-excellence-v.pdf archived at https://www.webcitation.org/78PpLYS1c.

3 Fintan G, Brown P. More than a prescription: what is the potential of medicines data? NHS England. https://www.england.nhs.uk/expo/wp-content/uploads/sites/18/2018/10/14.10-More-than-aprescription-what-is-the-potential-of-medicines-data.pdf archived at https://www.webcitation.org/78PpN1Ryz.

4 Ramkisson V. Transforming pharmacy services with technology. NHS Digital. https://digital.nhs.uk/blog/transformation-blog/2018/transforming-pharmacy-services-with-technology archived at https://www.webcitation.org/78PpMdY63.

5 NHS Digital. Practice level prescribing data. https://digital.nhs.uk/data-and-information/publications/statistical/practice-level-prescribing-data.

6 Walker AJ, Curtis HJ, Bacon S, Croker R, Goldacre B. Trends, geographical variation and factors associated with prescribing of gluten-free foods in English primary care: a cross-sectional study BMJ Open 2018;8:. . doi: 10.1136/bmjopen-2017-021312 pmid: 29661914

7 Walker AJ, Curtis HJ, Bacon S, Croker R, Goldacre B. Trends and variation in prescribing of low-priority treatments identified by NHS England: a cross-sectional study and interactive data tool in English primary care. J R Soc Med 2018;111:203-13. doi: 10.1177/0141076818769408 pmid: 29787684

8 Curtis HJ, Dennis JM, Shields BM, etal. Time trends and geographical variation in prescribing of drugs for diabetes in England from 1998 to 2017. Diabetes Obes Metab 2018;20:2159-68 . doi: 10.1111/dom.13346 pmid: 29732725

9 Curtis HJ, Walker AJ, Goldacre B. Impact of NICE guidance on tamoxifen prescribing in England 2011-2017: an interrupted time series analysis. Br / Cancer 2018;118:1268-75 doi: 10.1038/s41416-018-0065-2 pmid: 29681615

10 Croker R, Walker AJ, Bacon S, Curtis HJ, French L, Goldacre B. New mechanism to identify cost savings in English NHS prescribing: minimising 'price per unit', a cross-sectional study. BMJ Open 2018;8:. doi: 10.1136/bmjopen-2017-019643 pmid: 29439078
11 Walker AJ, Curtis HJ, Croker R, Bacon S, Goldacre B. Measuring the impact of an open online prescribing data analysis service on clinical practice: a cohort study on NHS England data. J Med Internet Res 2019;21.: doi: 10.2196/10929 pmid: 30664459

12 Gonem S, Cumella A, Richardson M. Asthma admission rates and patterns of salbutamol and inhaled corticosteroid prescribing in England from 2013 to 2017. Thorax 2019;74:705-6. doi: 10.1136/thoraxjn-2018-212723 pmid: 30630892

13 Saeed HS, Wright RB, Ghosh SK. Trends in the prescribing of topical nasal agents using an NHS England data base. Clin Otolaryngol 2018;43:1296-302. doi: 10.1111/coa.13143 pmid: 29770588

14 Edelstein M, Agbebiyi A, Ashiru-Oredope D, Hopkins S. Trends and patterns in antibiotic prescribing among out-of-hours primary care providers in England, 2010-14. J Antimicrob Chemother 2017;72:3490-5. . doi: 10.1093/jac/dkx323 pmid: 28961983

15 Croker R, Walker AJ, Goldacre B. Why did some practices not implement new antibiotic prescribing guidelines on urinary tract infection? A cohort study and survey in NHS England primary care. BioRxiv 355289 [Preprint]. https://www.biorxiv.org/content/10.1101/355289v1.full

16 Ivers N, Jamtvedt G, Flottorp S, etal. Audit and feedback: effects on professional practice and healthcare outcomes. Cochrane Database Syst Rev 2012;6: doi: 10.1002/14651858.CD000259.pub3 pmid: 22696318

17 Ashworth M, Armstrong D, Lloyd D, Colwill S. The effects on GP prescribing of joining a commissioning group. J Clin Pharm Ther 2002;27:221-8. doi: 10.1046/i.1365-2710.2002.00414.x pmid: 12081637

18 Rodgers S, Avery AJ, Meechan D, etal. Controlled trial of pharmacist intervention in general practice: the effect on prescribing costs. Br J Gen Pract 1999;49:717-20.pmid: 10756613

19 Avery AJ, Rodgers S, Cantrill JA, etal. A pharmacist-led information technology intervention for medication errors (PINCER): a multicentre, cluster randomised, controlled trial and cost-effectiveness analysis. Lancet 2012;379:1310-9. doi: 10.1016/50140-6736(11)61817-5 pmid.22357106

20 Public Health England. AMR local indicators. https://fingertips.phe.org.uk/profile/amr-local-indicators.

21 NHS England. Medicines optimisation dashboard-CCG. https://www.nhsbsa.nhs.uk/epact2/dashboards-and-specifications/medicines-optimisation-dashboard.

22 NHS England. NHS England Short Life Working Group on data driven care and early career pharmacy professionals. Supporting early career pharmacy professionals in data driven care: a guidance document for the profession. https://www.sps.nhs.uk/wp-content/uploads/2018/10/NHSEngland-report-Supporting-early-career-pharmacy-professional-in-data-Final._-1.pdf.

23 QuintilesIMS is now IQVIA. 2017.https://www.businesswire.com/news/home/20171106005380/en/QuintilesIMS-IQVIA archived at https://www.webcitation.org/78PpOxNQp.

24 Competitions Commission. Final Decision: Review of undertakings given by IMS Health Inc following its acquisition of Pharmaceutical Marketing Services Inc in 1999. https:/assets.publishing.service.gov.uk/media/5342be01e5274a571e000027/140325_finaL_decision_ims.pdf archived at https://web.archive.org/web/20190902161823/https://assets.publishing.service.gov.uk/media/5342be01e5274a571e000027/140325_final_decision_ims.pdf

25 NHS Digital. About NHS Digital. https://digital.nhs.uk/about-nhs-digital.

26 NHS Improvement. Sources of data for Pharmacy and Medicines-feedback on the Model Hospital. http://feedback.model.nhs.uk/knowledgebase/articles/1881736-sources-of-data-for-pharmacyand-medicines: archived at https://www.webcitation.org/78PpQ7afO.

27 Rx-Info. https://www.rx-info.co.uk/products/define/

28 East Kent Hospitals NHS Foundation Trust. Spend by Supplier: April 2019 https://www.ekhuft.nhs.uk/EasySiteWeb/GatewayLink.aspx?alld=468565 archived at https://web.archive.org/web/20190902161532/https://www.ekhuft.nhs.uk/EasysiteWeb/getresource.axd?AssetID=468565\&type=full\&servicetype=Attachment

29 Royal Cornwall Hospital NHS Trust. FOI Response: Suppliers and Expenditure. https://doclibrary rcht.cornwall.nhs.uk/DocumentsLibrary/RovalCornwallHospitalsTrust/Websites/Internet/OurOrganisation/FreedomOflnformation/DisclosureLog/2018/201808/FOIRef3949NHSPurchases.pd

30 Sheffield Teaching Hospitals NHS Foundation Trust. Procurement transparency payments Sep 2018. https://www.sth.nhs.uk/dlientfiles/File/PROC_TRANS_September\%202018.pdf archived at https://web.archive.org/web/20190902161738/https://www.sth.nhs.uk/clientfiles/File/PROC_TRANS_September\%202018.pdf

31 FOl response Bristol. http://www.uhbristol.nhs.uk/media/3122840/17-582___foi_response__attachment_a.pdf archived at https://web.archive.org/web/20190902161652/http://www.uhbristol.nhs.uk/media/3122840/17-582_-_foi_response_-_attachment_a.pdf

32 NHS Improvement. Who we are. https://improvement.nhs.uk/about-us/who-we-are/.

33 Lord Carter of Coles. Operational productivity and performance in English NHS acute hospitals: unwarranted variations. An independent report for the Department of Health by Lord Carter of Coles. 2016. https://assets.publishing.service.gov.uk/government/uploads/system/uploads/attachment_data/file/499229/Operational_productivity_A.pdf; archived at https:/www.webcitation.org/78PpPWbSX

34 NHS Improvement. Model Hospital. https://model.nhs.uk/.

35 NHS Improvement. Hospital pharmacy and medicines optimisation programme newsletter-June 2017. Specialist Pharmacy Service. https://www.sps.nhs.uk/wp-content/uploads/2017/08/HoPMOp-Newsletter-Aug-2017.docx 
36 NHS England. Devices and drugs taxonomy and monthly dataset specifications for 2018/19. https://www.england.nhs.uk/publication/devices-and-drugs-taxonomy-and-monthly-datasetspecifications-for-2018-19/ archived at https://webarchive.nation-

alarchives.gov.uk/20181103151257/https:/www.england.nhs.uk/nhs-standard-contract/ss-reporting/.

37 Public Health England. Systemic anti-cancer therapy dataset. http://www.chemodataset.nhs.uk/home.

38 NHS England. National Demand Management Programme for Immunoglobulin. Ig Database. http://igd.mdsas.com/ig-database/.

39 Department of Health and Social Care. Commercial Medicines Unit (CMU). GOV.UK. 2011.https://www.gov.uk/government/collections/commercial-medicines-unit-cmu archived at https://www.webcitation.org/78Pp07BEV.

40 NHS Clinical Commissioners. About CCGs. https://www.nhscc.org/ccgs/.

41 Define. RX-Info. https://www.rX-info.co.uk/products/define/ archive at https://www.webcitation.org/78PpRTyYo.

42 NHS Improvement. The NHS saves $£ 324$ million in a year by switching to better value medicines https://improvement.nhs.uk/news-alerts/nhs-saves-324-million-year-switching-better-valuemedicines/.

43 NHS Improvement. Model Hospital masterclass: understanding the top 10 medicines transition to 2018/19 targets. http://www.workcast.com/ControlUsher.aspx?cpak=9723777517945612\&pak=4486187118889407 archived at https://www.webcitation.org/78PpTnahh.

44 Department of Health and Social Care. The future of healthcare: our vision for digital, data and technology in health and care. GOV.UK. 2018.https://www.gov.uk/government/publications/thefuture-of-healthcare-our-vision-for-digital-data-and-technology-in-health-and-care/the-future-ofhealthcare-our-vision-for-digital-data-and-technology-in-health-and-care.

45 Naudet F, Sakarovitch C, Janiaud P, etal. Data sharing and reanalysis of randomized controlled trials in leading biomedical journals with a full data sharing policy: survey of studies published in The BMJ and PLOS Medicine. BMJ2018;360:k400. . doi: 10.1136/bmj.k400 pmid: 29440066

46 Walker AJ, Bacon S, Croker R, Goldacre B. Detecting change in comparison to peers in NHS prescribing data: a novel application of cumulative sum methodology. BMC Med Inform Decis Mak 2018;18:62. . doi: 10.1186/s12911-018-0642-6 pmid: 29986693

47 The Information Centre for health and social care (NHS). Evaluation and impact assessment-publication of practice-level prescribing data. https://webarchive.nationalarchives.gov.uk/20171011055710/http://content.digital.nhs.uk/media/10051/NHS-IC-Assessmentof-implications-of-publishing-practice-level-prescribing-datapdf/pdf/NHS_IC_Assessment_of_implications_of_publishing_practice_level_prescribing_data_300611.pdf

48 McCartney M. Margaret McCartney: The Care Quality Commission is not fit for purpose. BMJ 2014;349:g7460. . doi: 10.1136/bmj.g7460 pmid: 25499740

49 Siddique H. Care Quality Commission scraps “judgmental” GP practice bandings. Guardian 2015.https://www.theguardian.com/society/2015/mar/27/nhs-care-quality-commission-scrapsbandings-gp-practices.

50 Care Quality Commission. Update to GP intelligent monitoring. https://www.cqc.org.uk/news/stories/update-gp-intelligent-monitoring.

51 Supporting Information: Information Standards Notice. NHS Data Model and Dictionary Service, NHS Digital, First Floor, Vantage House, 40 Aire Street, Leeds, LS1 4HT. https://www.datadictionary.nhs.uk/data_dictionary/nhs_business_definitions/i/information_standards_notice_de.asp?shownav=1.

52 Blaveri DE. Mapping the landscape of UK health data research and innovation. Medical Research Council. 2017. https://mrc.ukri.org/documents/pdf/mapping-the-landscape-of-uk-health-dataresearch-and-innovation-report/ 